\title{
Hazards for buildings and structures caused by flood conditions
}

\author{
Krzysztof Wilk ${ }^{1, *}$ \\ ${ }^{1}$ Rzeszow University of Technology, Department Geodesy and Geotechnics, ul. Powstańców \\ Warszawy 12, 35-959 Rzeszów, Poland
}

\begin{abstract}
Floods are one of the common natural phenomena that can cause a huge danger to people and building objects located in flood plains. The particularly severe effects of such disasters are felt in heavily urbanized areas $[1,2]$. The development of river valleys causes difficulties in the flow of flood water and the protective embankments limit the possibility of the temporary accumulation of water. The consequence of this situation is increasing the level of the flood wave and thereby intensifying its negative impact.

Damages to the building during inundations can be the result of not only the direct activity of the flood wave and surface water, but also changes in groundwater flow conditions, including the increase of their piezometric level $[3,4]$. An increasing of groundwater pressure can intensify or initiate new phenomena related to permeability (suffosion, colmatation, etc.) and consequently conduce disadvantageous changes of soil substrate parameters [5]. The influence of such processes can be revealed later, after the floods stage recede. The local conditions of water flow and the ground structure have a direct impact on the probability of occurrence of specific phenomena threatening construction objects (initiated by floods).
\end{abstract}

\section{Introduction}

Floods are one of the natural phenomena that can cause a huge threat to people and building objects located in flood terrains. The negative impact of watercourse surges will not always be manifested only after they have burst from the banks - the reason for building damages cannot only be the direct action of water flowing on the surface. Underground water can also have unfavorable effects on structures - increasing its level or intensifying the flow into the ground.

The scale of flood hazards for building objects depends on two groups of considerations:

- natural - related to the geological and hydrological characteristics of the analyzed area and the climate there,

- anthropogenic - related to the transformation of the natural environment as a result of human intervention.

Natural factors pertain to:

\footnotetext{
* Corresponding author: kwilk@prz.edu.pl
} 
- geological landforms as a result of endogenous factors shaping the earth's surface, primarily in terms of heights, and exogenous factors having a major impact on the morphology of the terrain,

- development of the hydrological network in a given area, including the occurrence of specific surface forms of flowing and standing water, as well as a shallow and groundwater, - probability of occurrence of specific changes (extreme phenomena) in the area of weather cycles at that time.

Anthropogenic factors affecting the possibility and magnitude of damages during floods are:

- intensity and character of development of areas threatened by floods, which translates into the value of the property that the risk concerns,

- types and quality of artificial forms of protection of the area against flood waters, and regulation of their runoff.

The influence of natural and anthropogenic factors is interpenetrated and it is impossible to isolate the area associated only with one of these groups.

Even the gravitational runoff of surface waters is a form of erosion that shapes the surface of the terrain. The strength of this phenomenon increases with the increasing amount and speed of flowing water. This particularly takes place in the case of formed channels of the watercourses, but which are not always able to accommodate all rainwater and snowmelt. This causes flooding within the watercourses and their bursting from the established riverbeds, i.e. flood phenomena.

Virtually every spurt of flowing surface waters leaves a lasting mark in the natural environment. Damages that occurs with respect only to the natural environment often remained unnoticed or are deliberately ignored. They become a problem only when the damage relates to the infrastructure created by people. The scale of flood damage is therefore usually refers to structures or lost benefits from crops and other agricultural areas $[1,2]$. The values of destroyed material goods reported in the literature are difficult to compare due to the varying degree of urbanization of submerged lands. Such criteria and comparisons do not express the strength of freshets, and it seems impossible to set a uniform and universal measure in this area.

Human activities in areas threatened by floods usually have a limited impact on the possibility of an occurrence of extreme phenomena. The applied engineering protections may, to some degree, regulate the flow of water, but they cannot change the amount of water. In many cases, engineering forms of protection, accelerating the drainage of excess water in one place, cause the accumulation of flood waves in the area below. Therefore, the application of controlled water retention methods along the whole length of watercourses is of particular importance.

The water flow also takes place under the surface of ground. Increasing the amount of water in circulation during flood conditions increases the hydraulic pressure and flow velocity. This effect, apart from hydrodynamics on the ground skeleton, may cause changes in the geotechnical properties of the soil.

\section{Direct action of the flood wave}

Damages as those resulting from the impact of surface water (Fig. 1.) are caused by the dynamic action of flowing water current, hydrostatic pressure, destruction of ground surface, as well as activated by moisture and infiltration of water into the structure of building materials.

The dynamic effect of flowing water during freshets is visible primarily in the upper course of watercourses, where large differences in altitude increase the speed of water flow. The speed of water increases with its level in the riverbed, and natural obstacles: rock 
shelves and refractions of the route cease to fulfill the function of reducing the flow rate. The increase in speed directly involves an increase in pressure, with which the liquid works on encountered obstacles. It causes the mechanical damage of objects as a result of exceeding the strength of their elements.

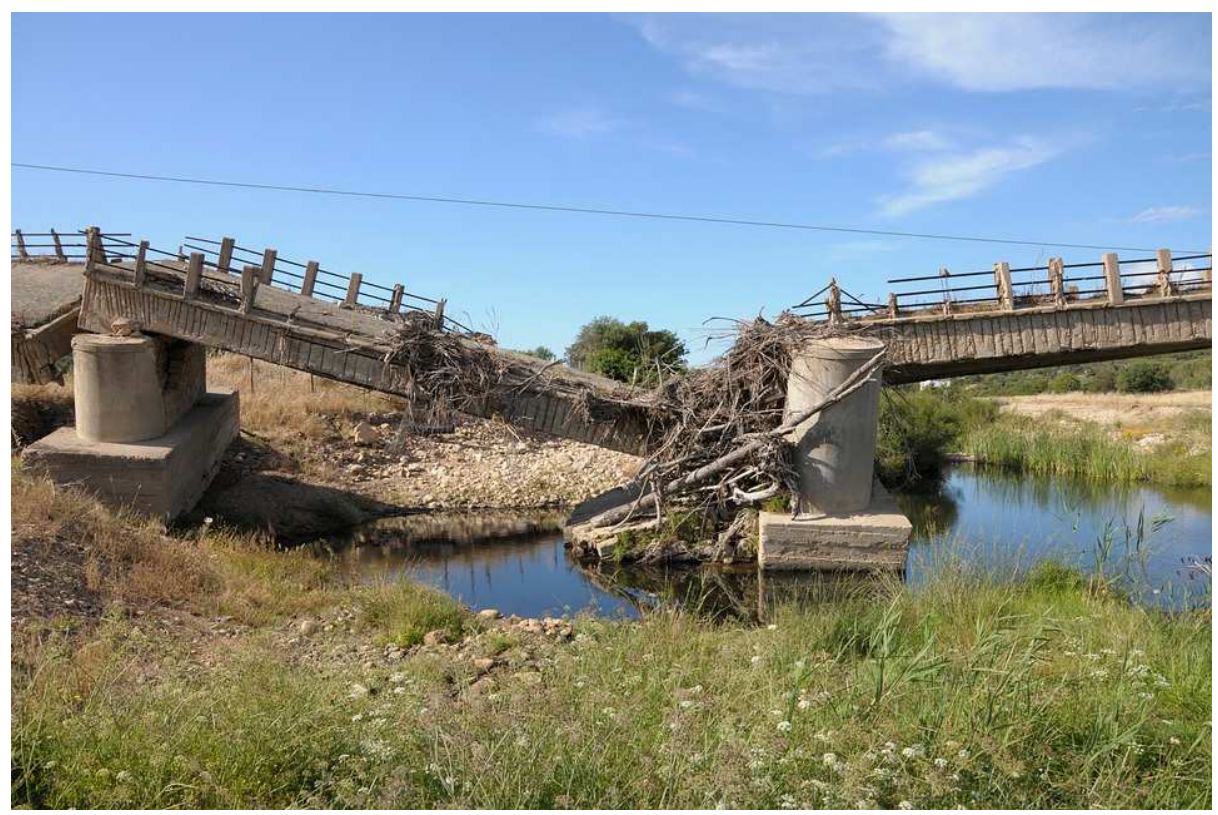

Fig. 1. Damages caused by the dynamic action of surface flood water https://pixabay.com/pl/sardynia-most-kawaler-upadek-1475156/ (access 21/02/2018)

The destructive action of surface water also takes place in relation to the ground. As a result of an increase in the flow velocity, the ground erodes, especially intense in places where obstacles are encountered, which are also construction objects. The erosion of foundations is a frequent cause of the collapse or emergency states of buildings.

In the lower sections of the rivers, along with the decrease of the downgrade of the watercourse decrease the speed of flowing water and the scale of dynamic impacts. Much greater, however, than in the upper tide of the amount of flowing water makes it that the potential threat does not diminish, but only changes its character. Much larger lands are then threatened by floods, and water outside the edges has more difficulties with leaving from flooded areas. Damages to buildings in the lower sections of rivers caused by direct water influence are usually related to damage and reduction of the parameters of building materials as a result of long-term hydrostatic pressure.

Not only are directly flooded areas jeopardized by flood water [3, 4]. Such an impact may also take place in areas protected, for example, by flood banks. In the case of the absence of surface direct water flow, the flow of groundwater is intensified. With unfavorable subsoil structure and insufficient seals of barrier, the water can flow out through or under the protection. Local exudations, depending on their intensity, may also directly affect building objects through hydrostatic thrusting above or below the surface of the terrain. 


\section{Influence of flood conditions on the ground}

\subsection{Water flow in the ground}

The ground is rock in solid or crumbled form. This fragmentation is a result of the intensity of the mostly exogenous processes that have been acting on the rock material over time. Since both the type and scale of these phenomena in the past has been variable, as well as the ground being lithologically diverse. Layers with different grain size, density and having different physical, mechanical and chemical properties have been created.

The flow of water taking place in the ground massif is much more intense in layers with a larger grain size - in non-cohesive soils. In cohesive soils it is often symbolic, and when these soils contain significant amounts of clay fraction, they are considered as waterimpermeable layers.

The flow of water in the soil depends mainly on its grain size, density and associated porosity, as well as on the mineral composition. The size of the pores in the ground, i.e. the size of the channels through which water can move, is the basic factor characterizing the filtration in soils with larger particle sizes. As the grain size is reduced, the average pore cross-section decreases, and the mineral composition of the soil particles is increasingly important for the water flow. The size of electrokinetic forces on the boundary surfaces of particles that attract water molecules, additionally hindering their movement in small channels, depends on the mineralogical structure. These factors have a discontinuous nature in the background (associated with the processes that shape this material) and, in a significant part, are random. In addition to the conditions associated with the ground material, the flow depends on the viscosity and possible biological and chemical contamination of the liquid.

Water naturally seeks to compensate any difference in hydraulic levels. In non-cohesive soils with larger grain sizes, the pores between particles also have larger dimensions. Under these conditions, the filtration of water takes place under the influence of gravity itself. In cohesive soils, the water flow must be initiated by a sufficiently high initial hydraulic gradient.

The ability of water flow in the ground is usually described by Darcy's Law, which in relation to its original form has been significantly modified over time, taking into account a number of additional factors that may affect the conditions of filtration. The parameter of water permeability referring to the ground medium itself is the permeability coefficient, in a broader sense understood as the permeability tensor. There are a number of methods for determining this quantity, both experimental and computational. The developed empirical formulas allow for estimating the Darcy constant in relation to other, usually physical, soil parameters. The research, in turn, can be divided into that which is conducted in the laboratory and in-situ. In-situ research is certainly a more accurate and reliable methodology for determining this parameter. In-situ studies allow for the consideration of all factors occurring in the ground on a macro scale, and which may be omitted during laboratory tests due to limited sample sizes.

\subsection{Changes of the flow in the ground during floods}

Groundwater is associated with the state of water in surface watercourses. Changes in the surface water level cause changes in the characteristic of water flow in the soil layers connected hydraulically with them. Increasing and lowering your table affect the value of the hydraulic gradient, and thus the direction and velocity of water flow in the ground.

With regard to flood states, three phases characteristic of groundwater flow can be distinguished (Fig. 2.): 
- phase 0 - normal flow of water in the normal state of surface waters (flow towards the open watercourse),

- phase I - change in the direction of water flow in the ground caused by surges of the watercourse (culmination of the flood wave, occurrence of water from the natural channel), - phase II - return to the normal direction of water flow, but with an increased hydraulic gradient (after the retreat of the flood wave).

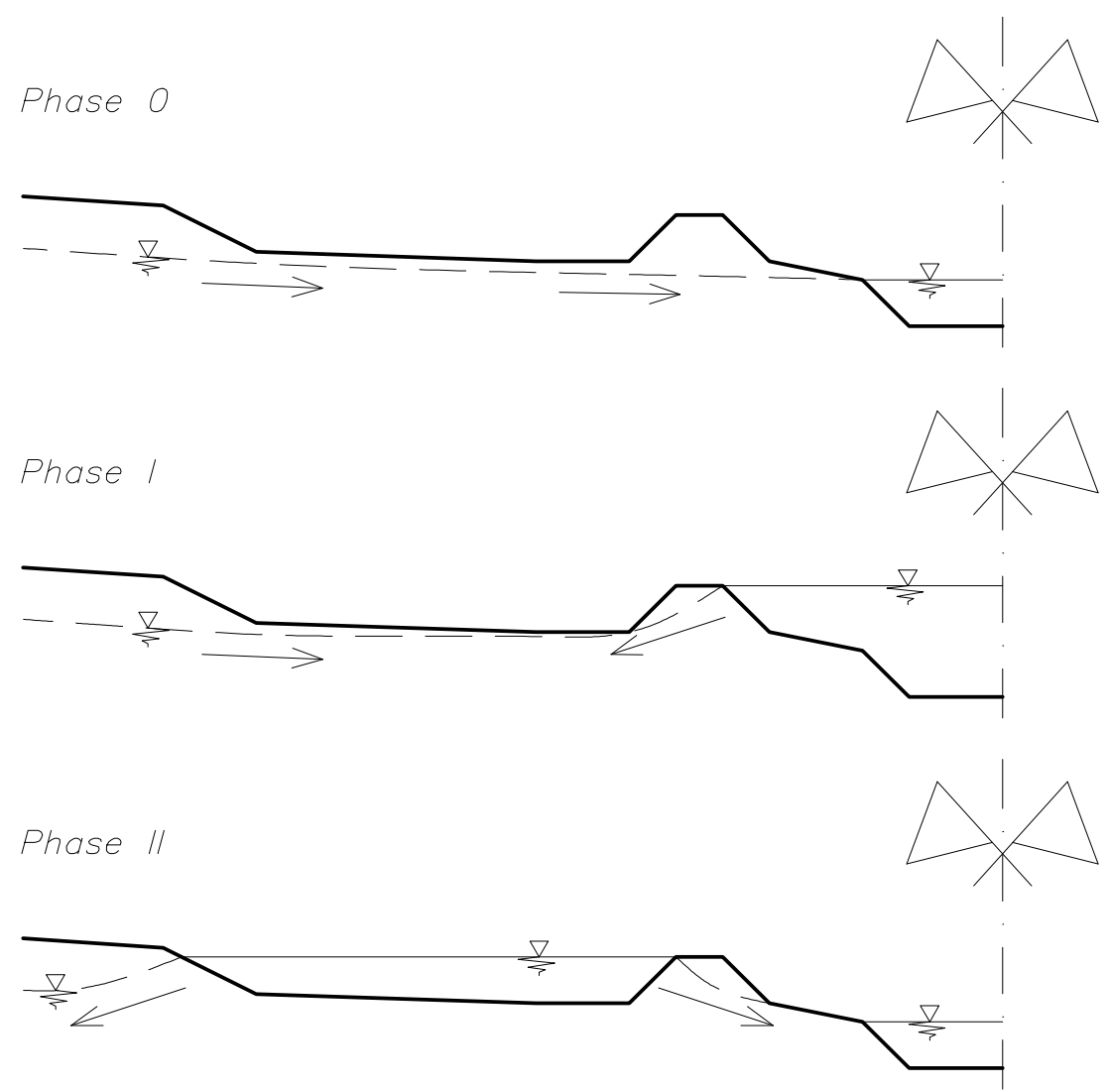

Fig. 2. Schematics of phases of groundwater flow during floods.

Flood states often cause changes in the directions of water flow in the ground and thus affect the ground skeleton. In addition, the water pressure can be changed multiple times. Structural changes can then appear in tubule net in the ground.

\subsection{Changes of the soil properties and their corollaries}

The impact of flood water on the ground is dependent on its structure [5]. Flood states have slightly different effects on the properties of soils with fine or coarser grains (cohesive or non-cohesive).

Changes in water flow in the ground may be accompanied by:

- changes in soil moisture and density related to:

- change in soil porosity,

- swelling,

- shrinkage, 
- suffosion or colmatation phenomena,

- boiling phenomena, seepage failure or hydraulic puncture.

In the case of non-cohesive soils, the increase of porosity is the result of the suffosion process, while the increase of density (reduction of porosity) is the result of the deposition of soil particles in the process of colmatation. Leaching the particles from the soil reduces its density, and consequently also causes an adverse change in strength and strain parameters.

The reason for the reduction of friction between the ground grains is the limitation of the number of contact places of the particles, as well as the filling of the pores by incompressible water, additionally under pressure. A significant increase of the soil porosity may lead to the loss of bearing capacity under construction objects and their damage.

Increasing the porosity of the soil, being the effect of the suffosion process, is observed not only during freshets - it is very often associated with the regulation of watercourses and drainage operations. Its consequence is settlement of the ground, which can be activated in a special way after the retreat of a flood wave due to the increase of the stress in the ground previously reduced by the upthrust of water.

The increase of water pressure in cohesive soils additionally intensifies its penetration into the soil structure. Attracting water molecules on the boundary surface of soil particles increases the moisture content of the ground, which translates into an increase of plasticity (liquidity index) and loss of strength parameters [6]. The soil particles are moved away from each other, which reduces the friction and cohesion between them.

Increasing the moisture of the soil, the amount of water in the ground is accompanied by an increase in its volume - the phenomenon of swelling is initiated. After the retreat of a flood wave, the soil moisture will decrease, and return to its original value before the flood - there will be a shrinkage of the ground.

Ground deformations are caused by swelling and shrinkage phenomena. The scale of deformations depends on the sensitivity of the soil to this type of phenomena - above all on grain size and mineral composition. The deformations themselves may occur unevenly, both in terms of their displacement value as well as the time and the area of their occurrence. Often, the nature of the shrinkage occurring after soil swelling is unrelated to the previous deformation. Unevenness of the deformation of the ground can especially lead to damage of construction objects, not only their foundations, but also elements and structures located higher, due to the often unanticipated deformed states and related stressed states in the building elements.

The drastic increase in the hydraulic gradient, usually observed during the retreat of the flood wave, may be the cause of boiling phenomena in the case of permeable soil, and in the case of blocking the flow through the cohesive ground of seepage failure or hydraulic puncture of the soil massif. As a consequence of colmatation, local soil compacting may hinder the flow of water. The increase of groundwater pressure in such cases may lead to fissures in the soil, preferential routes of filtration and the intensification of erosion processes in their vicinity.

\subsection{The specificity of ground and hazards on floodplains}

In areas threatened by flooding, two types of ground can be distinguished due to their origin:

- the ground developed as a result of exogenous and later endogenous processes where denudative processes dominate, preponderant in mountainous and upland areas,

- the accumulation origin soils, usually found in lowland areas. 
In the first case, it is difficult to talk about regularities in the structure of the ground. It is the result of geological processes that took place in the past in a specific location. Often there is rock at a small depth, in which flowing water erodes creating deep ravines. This erosion intensifies during freshets, also including the neighborhood of the watercourse.

The accumulation type of ground also has lithologicalvariability, however, it is the result of sedimentation processes of the material carried by surges of flood water. The ground formed as a result of river accumulation is commonly called fen soil [7]. Their common feature is theirorigin; whereas in granulometric terms they can be soils of various grain size. The content of organic parts is characteristic for the fen soils. However, the amount of organic material rarely allows qualifying these soils as typically organic.

The granulation of the dragged and deposited soil material depends on the speed of the flowing water. A ground with a dominant share of non-cohesive soils and cohesive soils can be differenced.

Non-cohesive fen soil is very often characterized by high porosity resulting from two reasons: the lack of consolidating loads and the occurrence of the suffosion phenomena.

In the case of cohesive fen soil, a characteristic feature is the layered structure, which is a reflection of sedimentation processes. Lamina with a thicker graining were deposited during higher strength freshet, and the weaker floods were left layers with finer particles. The thickness of said laminates is about a few millimeters. Such a specific structure affects the behavior of the ground during floods.

In homogeneous cohesive soil, the progress of moisture increase due to the low filtration coefficient is relatively slow. It is possible, that the weakening of the ground will not be able to cover a significant layer thickness before the retreat of flood waters, that is, the hydraulic gradient returns to its original value. The progress of soil moistening can be much more intense in the case of an alternating ground layered with fine and coarser grains (cohesive and non-cohesive). Water inside non-cohesive layers infiltrates much deeper into the ground massif and also covers a much larger volume of soil. The reason for this is the multiple greater contact area between the layers of fine and coarser graining. The described phenomenon may additionally increase in the case of discontinuity or damage of the continuity of cohesive layers. The vertical and horizontal differentiation of the flow through the layered ground structure was confirmed by research on the permeability coefficient carried out by the author [8]. The accelerated process of moisture and the loss of parameters is also observed for other soils being products of sedimentation processes of varying intensity in time, for example, the Krakowiec clays.

Flood terraces, of which there may be several levels, are limited by slopes. The channels of watercourses as well as oxbow lakes are also limited by scarps. These, together with flood embankments, are potential places for the activation of landslide processes during floods. The landslide hazard applies not only to areas with surface morphological diversity, but also to the neighborhood of oxbow lakes filled by the highly compressible soils, which are often unable to provide adequate resistance to forces generating slippage in the ground [5].

The direct cause of landslides may not only be changes in the structure and soil moisture described earlier. The culmination of the threat occurs during the floodwater's retreat. The soil within the slopes is earlier irrigated. The volumetric weight is increased, and at the same time as a result of increased moisture, the strength parameters of the soil are reduced. In addition, there eventuates a seepage pressure with a direction similar to the potential sliding surface. The convergence of time and place of these factors creates a very high landslide risk. 


\section{Summary}

The aim of the paper was to present a multitude of factors related to ground structure and conditioning the safety of building objects in floodplains.

Damage to the building during floods can be the result not only of the direct action of the flood wave and surface water, but also changes in groundwater flow conditions, including an increase in their piezometric level [3,4]. An increase in groundwater pressure may intensify or initiate new phenomena related to filtration (ceilings, colonization, etc.) and, consequently, lead to unfavorable changes in soil substrate parameters [5]. The impact of such processes may be revealed later, after the floods cease. The direct impact on the probability of occurrence of specific phenomena threatening construction objects, and initiated by flood, have local water flow conditions and the construction of the soil foundation.

Intensely built-up areas usually have solutions developed to protect them from the direct effects of floods. Often, however, the solutions used do not take into account all the risks that may arise in connection with the floods.

\section{References}

1. C.P. Konrad, Effects of Urban Development on Floods. US Geological Survey Hydrology Report, USGS Fact Sheet FS-076-03, (2003)

2. O.E.J. Wing, P.D. Bates, A.M. Smith, C.C. Sampson, K.A. Johnson, J. Fargione, P. Morefield, Estimates of present and future flood risk in the conterminous United States. Environmental Research Letter, 13, 034023, (2018)

3. D. Macdonald, A. Dixon, A. Newell, A. Hallaways, Journal of Flood Risk Management, 5 (1), 68-80 (2012)

4. K. Traczyński, M. Grela, The effect of changes in the groundwater level caused by flood in the Vistula river on the zoning in the Warsaw area. Biuletyn Państwowego Instytutu Geologicznego, 446 (2), 493-497 (2011) (in polish)

5. J. Jaremski, K. Wilk, The analysis of influence of mud soils humidity changes caused by flood states on geotechnical parameters. Zeszyty Naukowe Politechniki Rzeszowskiej. Budownictwo i Inżynieria Środowiska, z. 36 [208], 47-53 (2004) (in polish)

6. J. Jaremski, K. Wilk, Influence of fen soils moisture changes on the strength parameters and applied foundation solutions. Proceedings of the 10th International Congress of the IAEG, Nottingham, (2006)

7. E. Myślińska, Engineering-geological problems in investigations on soft soils in river valleys. 6th International IAEG Congress, Balkema, Rotterdam, (1990)

8. K. Wilk, Inżynieria Morska i Geotechnika, 1(28), 32-37 (2007) (in polish) 